\title{
The Biochemical and Genetic Odyssey to the Function of a Nicastrin-Like Protein
}

\author{
Christof Haffner Christian Haass \\ Laboratory for Alzheimer's and Parkinson's Disease Research, Department of Biochemistry, \\ Adolf Butenandt Institute, Ludwig Maximilians University, Munich, Germany
}

\section{Key Words}

$\gamma$-Secretase $\cdot$ Nodal $\cdot$ Nomo $\cdot$ Nicalin

\begin{abstract}
$\gamma$-Secretase is a high-molecular-weight protein complex required for the proteolytic processing of various transmembrane proteins including the Alzheimer's diseaseassociated amyloid precursor protein and the signaling receptor Notch. One of the $\gamma$-secretase complex components is the type I transmembrane protein nicastrin. Here we review the odyssey to a cyclopic fish, which at the end allowed the functional analysis of nicalin, a novel member of the nicastrin protein family. This $60-\mathrm{kDa}$ protein is part of a previously unknown membrane protein complex unrelated to $\gamma$-secretase and binds to Nomo (Nodal modulator, previously known as pM5), a novel $130-k D a$ transmembrane protein. Both proteins are highly conserved in metazoans and show almost identical tissue distribution in humans. Functional studies in zebrafish embryos and cultured human cells revealed that nicalin and Nomo collaborate to antagonize the Nodal/ TGF $\beta$ signaling pathway. Thus, nicastrin and nicalin are both associated with protein complexes involved in cell fate decisions during early embryonic development.
\end{abstract}

The $\gamma$-secretase cleavage is the final step in the proteolytic processing of various type I transmembrane proteins that have undergone ectodomain shedding, most importantly the amyloid precursor protein (APP) and the signaling receptor Notch $[1,2]$. Processing of APP leads to the generation of the amyloid- $\beta$ peptide, which is deposited in brains of Alzheimer's disease patients [3, 4]. The cleavage of Notch is required for the activation of the Notch signaling pathway, which mediates cell fate decisions at various stages during embryonic development $[5,6]$. The $\gamma$-secretase cleavage is unusual, since it occurs within the hydrophobic environment of the membrane and is mediated by a high-molecular-weight protein complex consisting of presenilins, nicastrin, APH-1 and PEN-2 [7, 8] (fig. 1a). The presenilins are polytopic transmembrane proteases which provide the active site of the $\gamma$-secretase complex [9]. The type I transmembrane protein nicastrin interacts with presenilins [10] and APH-1 [11] and is required for the assembly and stabilization of the complex. Its large extracytosolic domain contains a $\sim 200$-amino acid region which is predicted to adopt a fold similar to the aminopeptidase domain found in several aminopeptidases and the transferrin receptors [12]. The integrity of the aminopeptidase domain of nicastrin is necessary for $\gamma$ secretase activity $[10,13]$ and the maturation of the $\gamma$ secretase complex is accompanied by a change in the

\begin{tabular}{ll}
\hline KARGER & ( ) 2004 S. Karger AG, Basel \\
1660-2854/04/0015-0192\$21.00/0 \\
$\begin{array}{l}\text { Fax +41 61 306 1234 } \\
\begin{array}{l}\text { E-Mail karger@karger.ch } \\
\text { www.karger.com }\end{array}\end{array}$ & $\begin{array}{l}\text { Accessible online at: } \\
\text { www.karger.com/ndd }\end{array}$
\end{tabular}

Christof Haffner

Laboratory for Alzheimer's and Parkinson's Disease Research

Department of Biochemistry, Adolf Butenandt Institute, Ludwig Maximilians University Schillerstrasse 44, DE-80336 Munich (Germany)

Tel. +49 89218075 484, Fax +49 89218075 415, E-Mail chaffner@med.uni-muenchen.de 
Fig. 1. Nicalin is a nicastrin-related protein. a Intramembrane proteolysis of APP by the $\gamma$-secretase complex. APP is first cleaved by $\beta$-secretase (arrowhead) to generate C99, the substrate for $\gamma$-secretase. C99 then enters the $\gamma$-secretase complex (gray box) which consists of presenilins (PS), nicastrin, PEN-2 and $\mathrm{APH}-1$. The two critical aspartates in the transmembrane domains 6 and 7 of PS N-terminal (NTF) and C-terminal (CTF) fragments mediate endoproteolysis of $\mathrm{C} 99$ resulting in the secretion of amyloid- $\beta$ peptide and the liberation of AICD (APP intracellular domain). b Phylogenetic tree showing that the nicalins are more closely related to nicastrins than to transferrin receptors and active aminopeptidases. NAALADL $=$ N-Acetyl- $\alpha$-linked acidic dipeptidase-like protein; PSMA = prostate-specific membrane antigen; TFR = transferrin receptor; $\mathrm{NCL}=$ nicalin; $\mathrm{NCT}=$ nicastrin; $\mathrm{HS}=$ Homo sapiens; $\mathrm{RN}=$ Rattus novegicus; $\mathrm{MM}=$ Mus musculus $; \mathrm{DM}=$ Drosophila melanogaster; $\mathrm{CE}=$ Caenorhabditis elegans; $\mathrm{AT}=$ Arabidopsis thaliana .

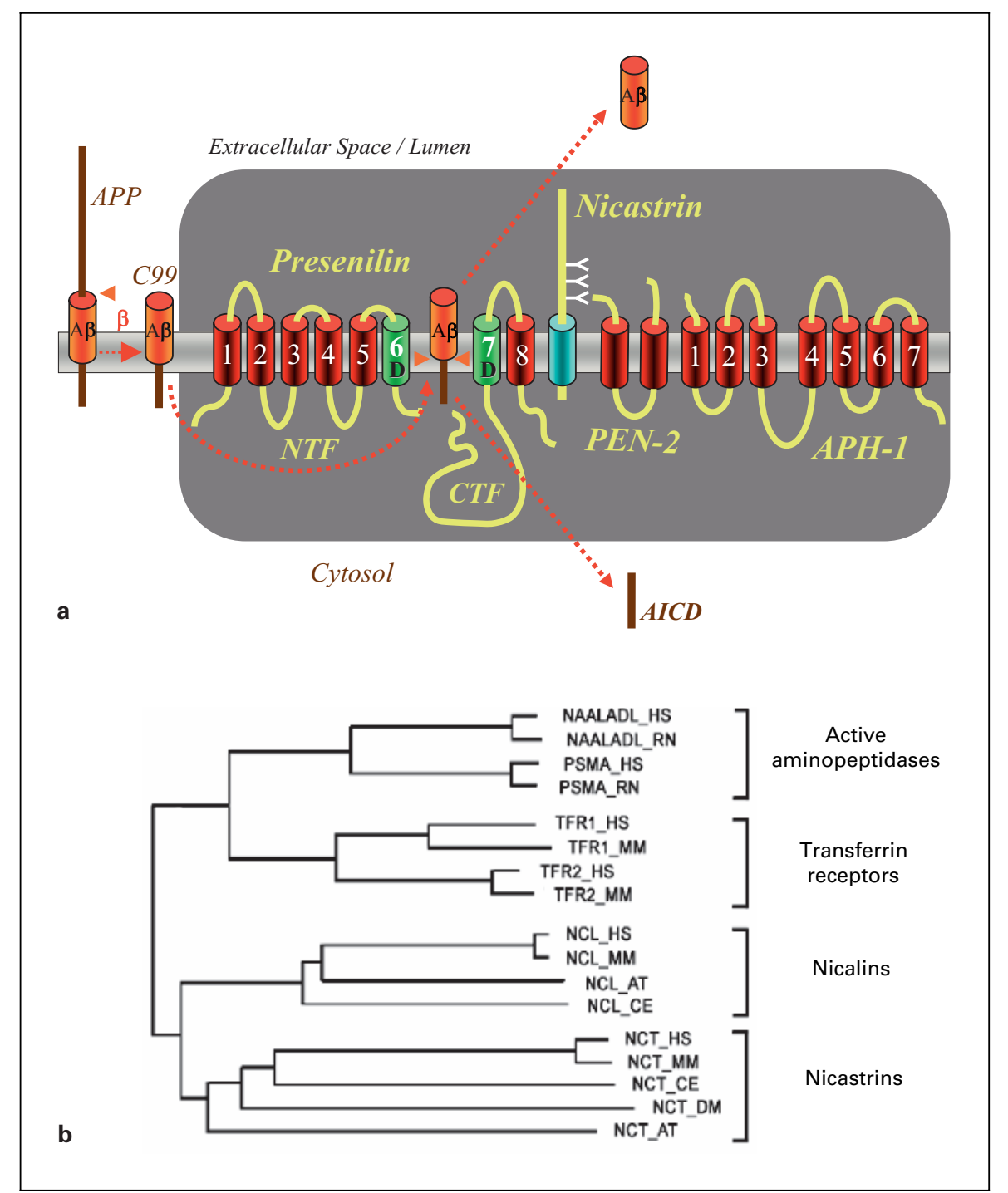

structure of nicastrin [13]. Since none of the $\gamma$-secretase complex components can act by themselves, the identification of the individual functions of the components is extraordinarily difficult.

In an attempt to gain further insight into the mode of action of nicastrin, we searched for nicastrin-related proteins by scanning protein and genome databases with generalized profiles constructed from the ectodomain of the nicastrin family [14]. This search identified a novel putative transmembrane protein with the same phyletic distribution as nicastrin (fig. 1b). Since this protein is predicted to represent a type I transmembrane protein with the same overall architecture as nicastrin, we refer to it as nicalin (nicastrin-like protein). The sequence similarity is confined to a region of 180 residues, which roughly corre- sponds to the previously described aminopeptidase domain. Analysis of nicalin by blue-native polyacrylamide gel electrophoresis revealed its presence in a high-molecular-weight membrane protein complex with a size surprisingly similar to $\gamma$-secretase (fig. 2a). However, in nicalin immunoprecipitates, $\gamma$-secretase components were not detected demonstrating that that these complexes are completely unrelated [14]. Instead, a $130-\mathrm{kDa}$ protein coprecipitated with nicalin (fig. 2b) which was identified by mass spectrometry as pM5, a protein of unknown function. Based on the results of our analysis in zebrafish embryos (see below), we refer to it as Nomo (Nodal modulator). The significance of the nicalin/Nomo interaction is further underscored by the following observations: (1) orthologs of both proteins can be found in invertebrates 
Fig. 2. The nicalin/Nomo complex is involved in cell fate decisions during zebrafish embryogenesis. a Immunoblot of blue-native gels of membrane protein extracts from HEK293 cells expressing the APP Swedish mutant $(\mathrm{Sw})$ and nicalin $(\mathrm{Sw} / \mathrm{Ncl})$. Nicalin immunoreactivity is seen in a high-molecular-weight complex with a size similar to $\gamma$ secretase, which is detected with an anti-presenilin 1 antibody ( $\alpha$-PS1). b Coomassiestained SDS gel containing proteins immunoprecipitated with $\alpha$-nicalin antibodies from $\mathrm{Sw}$ or $\mathrm{Sw} / \mathrm{Ncl}$ cell membrane preparations. A $60-$ and a 130-kDa band were specifically enriched in precipitates from $\mathrm{Sw} / \mathrm{Ncl}$ cells $*^{*}=$ immunoglobulin heavy chain). Peptide mass fingerprints generated by MALDI analysis identified these bands as nicalin and pM5, which we refer to as Nomo. c Coexpression of ncll and nomo in zebrafish embryos affects cell fate decisions leading to cyclopia. $36 \mathrm{~h}$ postfertilization morphology of a wild-type embryo (top panel) and an embryo coinjected with ncll and nomo capped RNAs (bottom panel). Note the prominent cyclopia of the injected embryo (arrow).

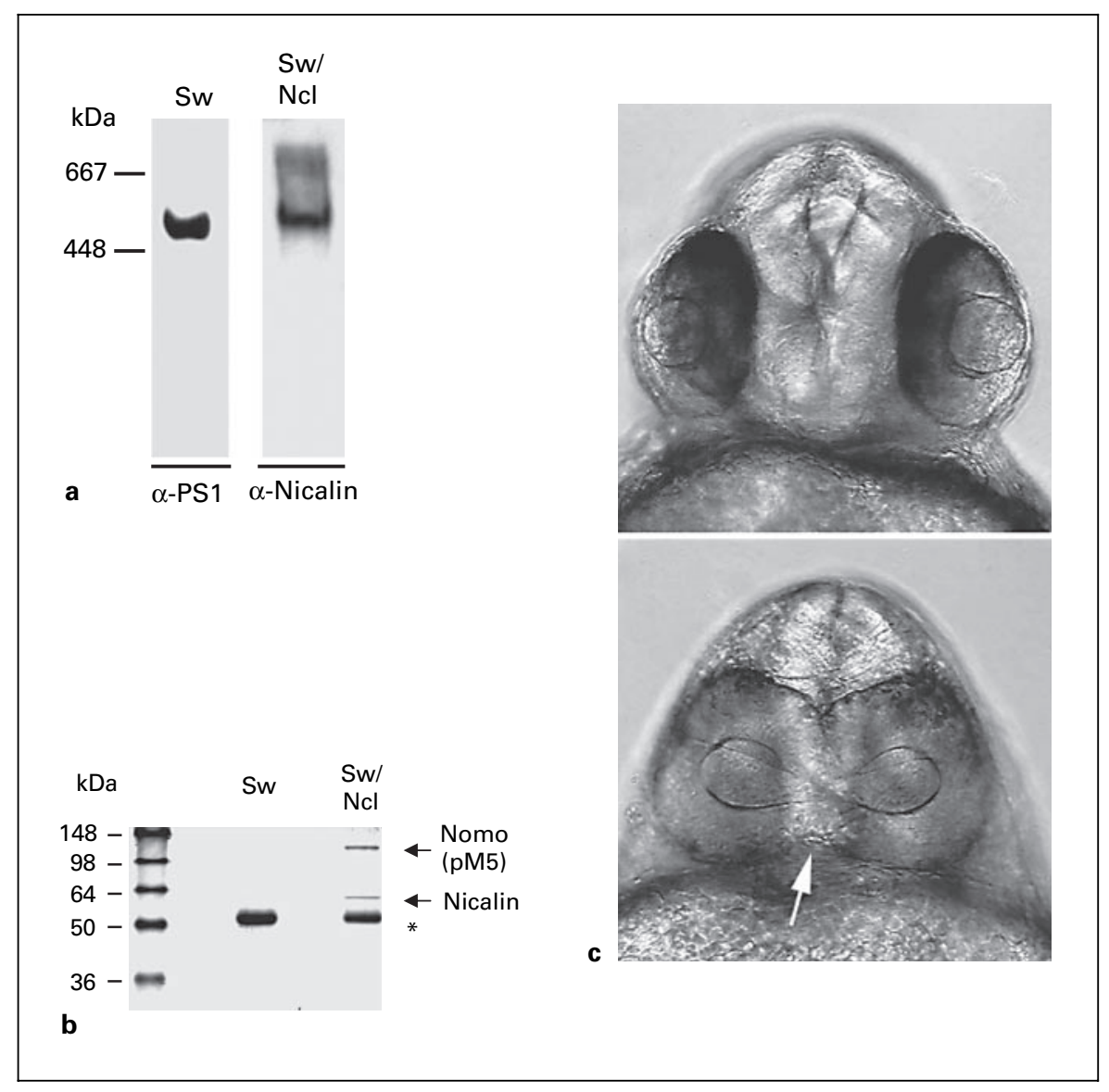

Fig. 3. Model of the inhibition of Nodal/TGF $\beta$ signaling by the nicalin/Nomo complex. TGF $\beta$ ligands act via dimeric kinase receptors (ActRIIB and ALK4) which activate signal transducers of the Smad family [19]. In the nucleus, protein complexes containing Smad proteins and transcription factors are formed which activate the transcription of target genes. The binding of Nodal (but not TGF $\beta$ or activin) to its receptor requires a coreceptor of the EGF-CFC family (Oep/Cripto). The specific Nodal inhibitor Lefty acts by inactivating Oep/Cripto (or Nodal itself). In contrast, the nicalin/Nomo complex appears to antagonize Nodal/TGF $\beta$ signaling at a more downstream step. Oep = One-eyed pinhead; ActRIIB = activin-type receptor IIB; Alk4 = activin receptor-like kinase 4; FoxHI/FAST2 = forkhead transcription factor.

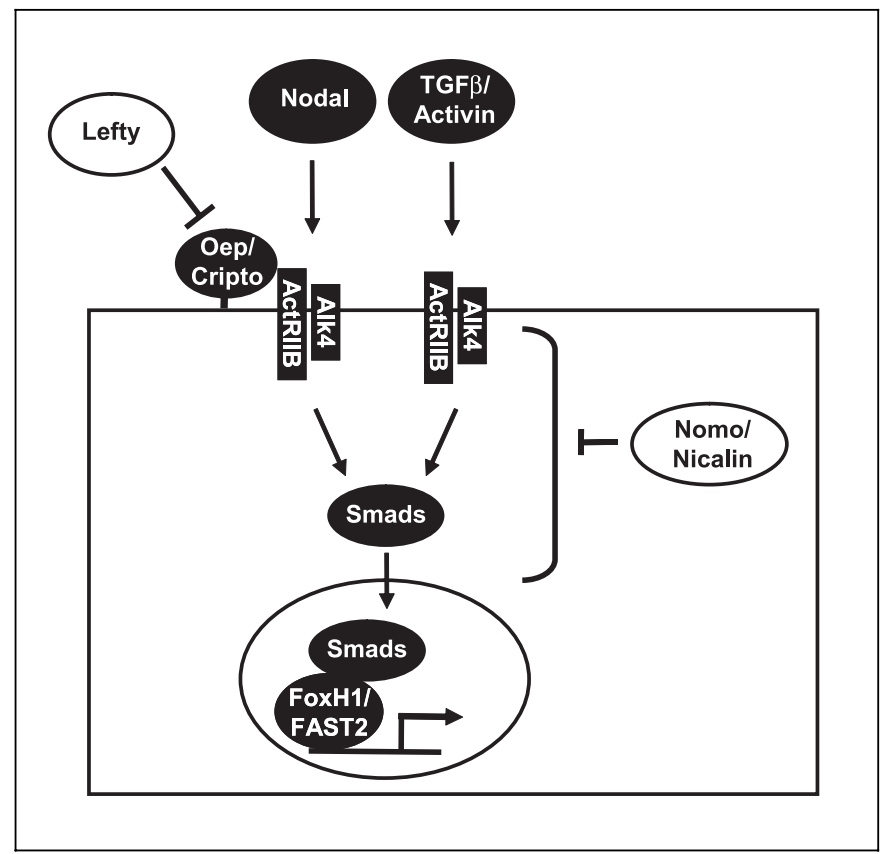

Haffner/Haass 
and plants (fig. 1b), (2) their tissue distribution is highly similar in humans [14] and (3) both nicalin and Nomo localize to the endoplasmic reticulum (unpubl. data).

To identify the biological function of this novel protein complex, we used the zebrafish system which has been successfully used to recapitulate the defects in somite formation associated with the inhibition of Notch signaling [15]. One Nomo (nomo) and two nicalin orthologs (ncll, $n c l 2$ ) were found in the zebrafish genome. Interfering with nomo and/or ncll expression levels in zebrafish embryos failed to produce phenotypes related to Notch signaling deficiencies, pointing to the distinct functions of the $\gamma$-secretase and the nicalin/Nomo complex in vivo [14]. In contrast, we found that ectopic coexpression of Nomo and Ncl1, but not of each factor alone, led to cyclopic, 'squint-eyed' embryos (fig. 2c). Blocking the production of Nomo with an antisense oligonucleotide resulted in the development of a massively enlarged hatching gland [14]. Both phenotypes can arise through a failure in the proper patterning of embryonic mesendodermal tissue $[16,17]$, a process regulated by the TGF $\beta$ factor Nodal [18]. In situ hybridization experiments indeed demonstrated that downregulation of Nomo increased the amount of anterior axial mesendoderm indicating enhanced Nodal signaling [14]. These data pointed to an antagonistic role of the nicalin/Nomo complex in the Nodal pathway and were confirmed by the finding that enhanced inhibition of Nodal signaling by the overexpression of the specific Nodal inhibitor Lefty was counteracted by blocking Nomo expression [14]. To analyze if nicalin and Nomo affect Nodal signaling directly, a luciferase reporter assay in human embryonic kidney 293T cells was established. Overexpression of nicalin or Nomo in these cells dose-dependently reduced luciferase activity derived from a TGF $\beta$-responsive promoter [14]. We, thus, propose a direct role for the nicalin/Nomo complex in the modulation of Nodal/TGF $\beta$ signaling (fig. 3).

Taken together these recent findings suggest that proteins of the nicastrin family may have evolved to fulfill biological functions in cell fate decisions during early embryogenesis. Interestingly, the function of these proteins in Notch and Nodal signaling is associated with a high-molecular-weight protein complex.

\section{Acknowledgement}

This research was supported by the European Union under the programme 'Quality of Life and Management of Living Resources', Key Action 3 'The Cell Factory', Contract No. QLK3-CT-200102362 .

\section{References}

$>1$ Selkoe DJ: Alzheimer's disease: Genes, proteins, and therapy. Physiol Rev 2001;81:741766.

$>2$ Fortini ME: $\gamma$-Secretase-mediated proteolysis in cell-surface-receptor signalling. Nat Rev Mol Cell Biol 2002;3:673-684.

3 Sisodia SS, St George-Hyslop PH: Gammasecretase, Notch, Abeta and Alzheimer's disease: Where do the presenilins fit in? Nat Rev Neurosci 2002;3:281-290.

4 Hardy J, Selkoe DJ: The amyloid hypothesis of Alzheimer's disease: Progress and problems on the road to therapeutics. Science 2002;297: 353-356.

$\checkmark 5$ De Strooper B, Annaert W, Cupers P, Saftig P Craessaerts K, Mumm JS, Schroeter EH, Schrijvers V, Wolfe MS, Ray WJ, Goate A, Kopan R: A presenilin-1-dependent $\gamma$-secretase-like protease mediates release of Notch intracellular domain. Nature 1999;398:518522.

-6 Selkoe D, Kopan R: Notch and presenilin: Regulated intramembrane proteolysis links development and degeneration. Annu Rev Neurosci 2003;26:565-597.

7 Haass C, Steiner H: Alzheimer disease $\gamma$-secretase: A complex story of GxGD-type presenilin proteases. Trends Cell Biol 2002;12:556-562.
$>8$ Edbauer D, Winkler E, Regula JT, Pesold B, Steiner H, Haass C: Reconstitution of $\gamma$-secretase activity. Nat Cell Biol 2003;5:486-488.

9 Wolfe MS, Xia W, Ostaszewski BL, Diehl TS, Kimberly WT, Selkoe DJ: Two transmembrane aspartates in presenilin-1 required for presenilin endoproteolysis and $\gamma$-secretase activity. Nature 1999;398:513-517.

$10 \mathrm{Yu}$ G, Nishimura M, Arawaka S, Levitan D, Zhang L, Tandon A, Song YQ, Rogaeva E, Chen F, Kawarai T, Supala A, Levesque L, Yu H, Yang DS, Holmes E, Milman P, Liang Y, Zhang DM, Xu DH, Sato C, Rogaev E, Smith M, Janus C, Zhang Y, Aebersold R, Farrer LS, Sorbi S, Bruni A, Fraser P, St George-Hyslop P: Nicastrin modulates presenilin-mediated notch/glp-1 signal transduction and uAPP processing. Nature 2000;407:48-54.

11 Morais VA, Crystal AS, Pijak DS, Carlin D, Costa J, Lee VM, Doms RW: The transmembrane domain region of nicastrin mediates direct interactions with APH-1 and the gammasecretase complex. J Biol Chem 2003;278: 43284-43291.

12 Fagan R, Swindells M, Overington J, Weir M: Nicastrin, a presenilin-interacting protein, contains an aminopeptidase/transferrin receptor superfamily domain. Trends Biochem Sci 2001;26:213-214.
Biochemical and Genetic Odyssey to the

Function of a Nicastrin-Like Protein
Neurodegenerative Dis 2004;1:192-195 